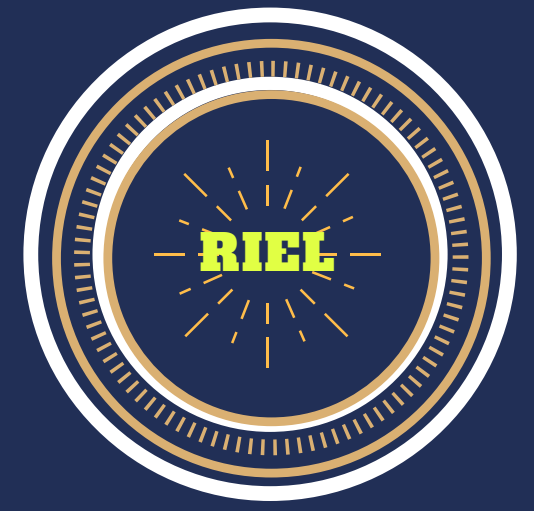

Revista Interdisciplinar em Estudos de Linguagem

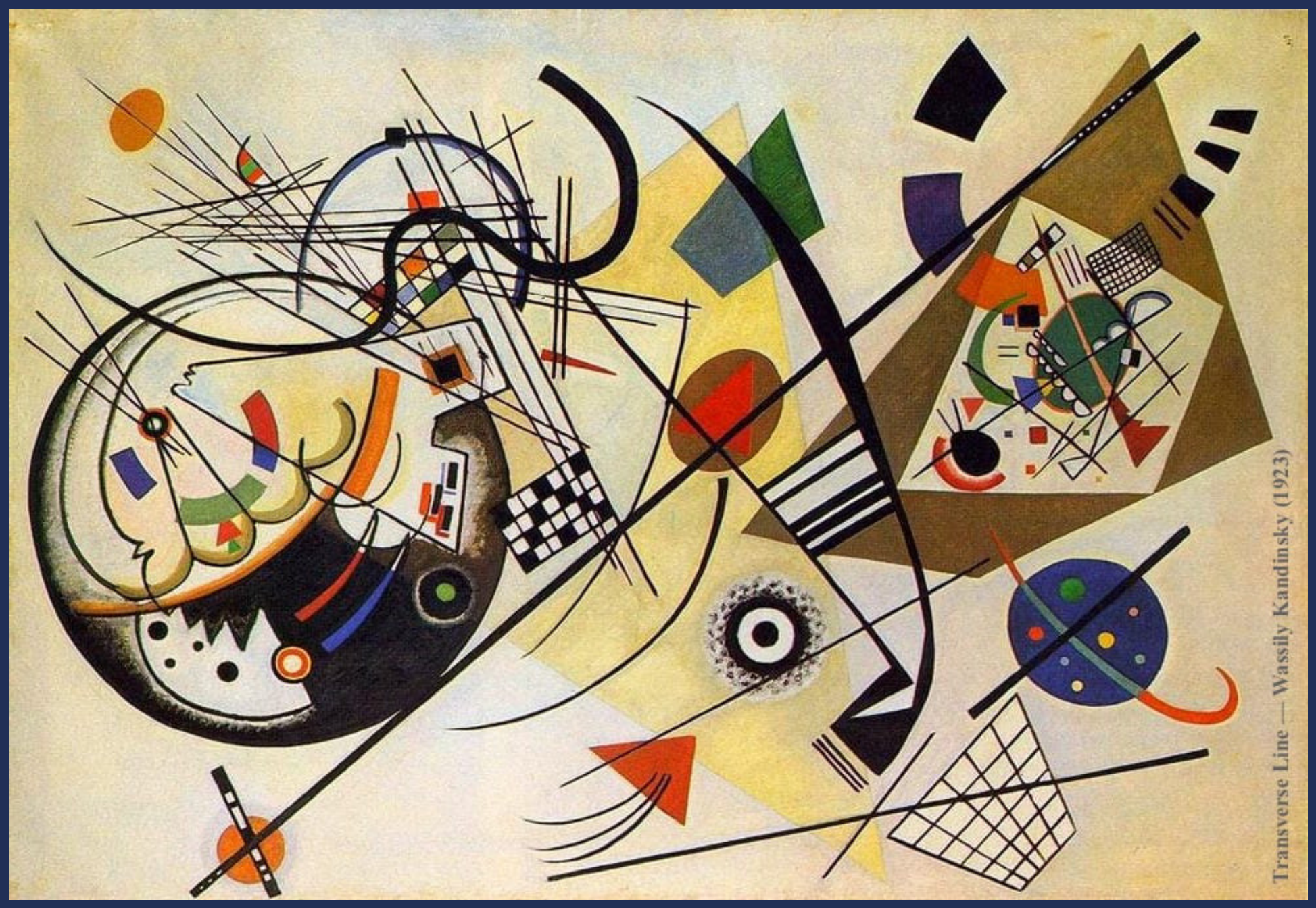

Volume 1 - Número $1 \cdot 2019$ 


\section{QUE RUFEM OS TAMBORES E SOEM OS CLARINS! 12}

fluxo contínuo

As temáticas do fluxo contínuo deste primeiro número da Revista Interdisciplinar em Estudos de Linguagem estão relacionadas à discussão crítica que se volta à produção textual dialógica, ao uso de tecnologias de informação e comunicação, à cinematografia, à abordagem de questões afrobrasileiras por meio de histórias orais e em quadrinhos, à cultura e identidades surdas, à apropriação da Grounded Theory em uma sucinta revisão sob as lentes dos Estudos de Linguagem, ao ensino-aprendizagem de Português para falantes de outras línguas e, por fim, à uma possível releitura da obra de Dom Quixote de Miguel de Cervantes.

As pesquisadoras Ester Maria de Figueiredo Souza da Universidade Estadual do Sudoeste da Bahia (UESB) e Islene dos Santos Roque Benevides do Instituto Federal da Bahia (IFBA), assinam o artigo Estratégias discursivas: um recorte dialógico da aula. Em seu texto abordam a constituição das interações na aula de produção textual e ancoram sua discussão na teoria dialógica proposta por Mikhail Bakhtin. Consideram o tema ao analisar as atividades de um livro didático.

$\mathrm{O}$ artigo seguinte é conformado por uma parceria entre pesquisadores do Brasil e da França e foi redigido em Francês. Intitula-se $O$ leitor da era digital e o ensino de literatura: a busca do sentido por meio da teoria da recepção - ensino médio brasileiro em análise. Seus autores são Eduardo Dias da Silva e Lucimar Pinheiro da Silva Sampaio, ambos da Universidade de Brasilia (UnB) e Aura Luz Duffé que é pesquisadora do Laboratório Linguistique, Ingénierie, Didactique des Langues (LIDILE) da Université de Rennes 2. Em seu texto, os colegas brasileiros e franceses tratam do problemático distanciamento e desinteresse do alunado na educação básica pelo estudo de Literatura. Abordam essa questão sob um prisma paradoxal dado o facilitado acesso à informação e comunicação mediadas pelas tecnologias. Fundamentam sua discussão na teoria da recepção.

Renato de Oliveira Dering do Centro Universitário de Goiás (Uni-ANHANGUERA) e Vanessa Silva Andrade da Universidade Federal de Goiás (UFG) são os autores do texto O palhaço, de Selton Mello, e a discussão do eu frente à construção da narrativa do sujeito. Fazem, em seu artigo, uma reflexão sobre as possibilidades que o cinema abre para a abordagem de questões de identidade. Pautam seus apontamentos e narrativas nas obras de Zygmunt Bauman e Stuart Hall.

O próximo texto leva o título Possibilidades metodológicas para um ensino (crítico!) de História no ensino fundamental e é de autoria de Tassio Acosta da Universidade Estadual de Campinas (UNICAMP). Nesse texto, Acosta busca valer-se de histórias locais, orais e em

\footnotetext{
${ }^{1}$ Rubens Lacerda de Sá ${ }^{\circledR}$

2 DOI https://doi.org/10.29327/2.1373.1-1
} 
quadrinhos alinhadas com os Parâmetros Curriculares Nacionais para abordar questões sobre africanidades e brasilidades. $\mathrm{O}$ que almeja são novas possibilidades metodológicas para o desenvolvimento de uma prática docente interessante, crítica e contextualizada.

Da Universidade Federal Mato Grosso (UFMT) e sob a batuta de Claudio Alves Benassi vem o artigo Além dos sentidos: cultura e identidade surdas como discurso capitalístico de produção de subjetividades e serialização do ser visossinalizante. Este intrigante artigo discute a relação identidade, cultura e produção de subjetividades surdas a partir da concepção de micropolítica de Félix Guattari e Suely Rolnik. Também aborda a singularização do ser visossinalizante nas esferas cotidiana e acadêmica, bem como a cultural e artística.

Rubens Lacerda de Sá buscou na Sociologia Clínica uma abordagem metodológica que pudesse ser apropriada e relida pelas lentes dos estudos de linguagem. Essa empreitada resultou no ensaio Grounded Theory e os Estudos de Linguagem: uma releitura. Seu texto é fruto de pesquisas na Universidade Estadual de Campinas (UNICAMP), no Centro Latino-Americano de Estudos em Cultura (CLAEC) e no Instituto Federal de Educação, Ciência e Tecnologia de São Paulo (IFSP). Nele, Sá pretende obsequiar aos leitores com uma releitura crítica e reflexiva dos princípios norteadores da Grounded Theory e suas potencialidades para os Estudos de Linguagem.

Incluímos nesta parte do número um desta revista uma resenha assinada por dois jovens graduandos do Instituto Federal de Educação, Ciência e Tecnologia de São Paulo (IFSP), Gabriel Marques da Silva e Carlos Eduardo Martins de Lima. Embora estudantes de Física, os autores se propõem a resenhar uma obra da área de Letras e Linguística intitulada Português para falantes de outras línguas: interculturalidade, inclusão social e políticas linguísticas. Seu principal desafio foi alinhá-la à ciência que estudam na universidade.

Viviane Barbosa Rasga Aires, docente de Língua Portuguesa e Literatura do Centro Estadual de Educação Tecnológica de São Paulo (CEETEPS), nos apresenta o primeiro relato de experiência em sala de aula a partir de uma releitura da obra Dom Quixote de Miguel de Cervantes. Seu intuito era averiguar os diferentes níveis de proficiência e habilidade leitora de seus alunos. O título de seu relato de experiência é Loucura ou ficção? Uma leitura de Dom Quixote.

Por fim, embora não menos relevante, concluímos esta primeira parte com outro relato de experiência. A graduanda em Pedagogia pela Universidade Virtual do Estado de São Paulo (UNIVESP), Márcia Quirino Ferreira Oliveira, inquieta com a falta de protagonismo de seus alunos, a ausência de um trabalho interdisciplinar efetivo na escola e a não relação entre os textos lidos e o desenvolvimento de habilidades diversas nos distintos componentes curriculares da educação básica, realizou a atividade $O$ texto como pretexto: ler ou não ler, eis a questão!. Trata-se de uma proposta que mobilizou seus alunos e colegas docentes de português, literatura, biologia, filosofia e sociologia. Abordaram conteúdos programados a suas disciplinas através do gênero literário contos. 
O marco zero da proposta deste dossiê é o reconhecimento de que a interdisciplinaridade, e mais ainda em sua relação com linguagem, continua a representar um gigantesco desafio epistêmico-metodológico nos espaços e produções acadêmicas, pois muito se enuncia e pouco se pratica. Isso denota a complexidade da temática em tela e o que, em primeira instância, mobilizou os editores deste número a convidar pesquisadores para expor suas trajetórias de investigação e seus processos de reelaboração conceitual em contextos culturais múltiplos, diversos e complexos.

Neste dossiê são contemplados sete artigos. Abrangem áreas como Geografia, Filosofia e Literatura, História, Metodologias Ativas, Sociologia, Matemática e Linguagem. Como na primeira parte, aqui também promove-se uma discussão crítica dos temas apresentados com o fito de propiciar ao leitor uma reflexão voltada às questões sociais em voga.

Abrimos com o texto Povos indígenas e injustiça etnoambiental na formação territorial brasileira escrito por Marjana Vedovatto, docente de geografia do Instituto Federal de Educação, Ciência e Tecnologia de São Paulo (IFSP). No texto, a autora aborda conceitos como injustiça e racismo ambiental, formação territorial brasileira pós-colonização, expropriação territorial dos povos originários e, por fim, discorre acerca do alerta para injustiças etnoambientais.

Por meio de um viés filosófico-fenomenológico a partir da hermenêutica de Martin Heidegger, Norival Bottos Júnior e Cacio José Ferreira, da Pontifícia Universidade Católica de Goiás (PUC/GO) e Universidade Federal do Amazonas (UFAM) respectivamente, nos oferecem o texto Leituras fenomenológicas da hermenêutica heideggeriana em "A hora da estrela" de Clarice Lispector. Com essa proposta, os autores buscam, nas tramas da narrativa em questão, diferenciar o ôntico, o ontológico e o pré-ontológico para estabelecer uma relação entre a existência e o existencial. Também nos contemplam com a conceituação do dasein. Tudo isso via literatura.

Seguindo viagem no dossiê, embarcamos na História com Iamara Nepomuceno da Universidade de São Paulo. Seu texto intitula-se A construção de narrativas eurocêntricas na sociedade zambeziana do século XIX. Nele, Iamara, explica o que eram os prazos zambezianos e sua relação com a cultura afro-portuguesa, os embates político-ideológicos e a transformação social e econômica naquela sociedade. Tudo perpassado pelas ações de uma mulher, Luísa do Goengue.

$\mathrm{Na}$ seara da linguagem, temos o texto Metodologias ativas para o ensino de Inglês e Espanhol no ensino médio profissionalizante cujas autoras são Elkerlane Martins de Araújo 
Moraes e Graziani França Claudino de Anicézio, ambas do Instituto Federal de Educação, Ciência e Tecnologia do Tocantins (IFTO). Sua proposta com esse artigo é tratar dos desafios confrontados pelos docentes de cursos profissionalizantes entre a educação propedêutica e a técnica. As pesquisadoras propõem o uso de metodologias ativas como um caminho possível.

André Rocha Santos, sociólogo do Instituto Federal de Educação, Ciência e Tecnologia de São Paulo (IFSP) e Alessa Coelho Lauriano, graduanda em Ciências Sociais pela Universidade Federal do Paraná (UFPR), fazem uma análise de um material didático para o ensino de Sociologia na educação básica média com o objetivo de constatar se esse alinha-se com o que é proposto pelo Programa Nacional do Livro Didático (PNLD). Seu artigo tem o tema Leviatã para jovens? O conceito de Estado nos livros didáticos de Sociologia.

Etnomatemática é tanto uma palavra como um conceito e uma prática ainda pouco difundidas na escola brasileira. Por isso que o texto, Pensar a etnomatemática: o cotidiano rural como lugar autêntico de revelação do conhecimento, de Jândela Cristiani Guilherme dos Santos Tamashiro, candidata ao doutorado pela Universidade Federal de São Paulo (UNIFESP), é muito bem-vindo para compor esse dossiê. A partir de uma pesquisa em uma zona rural nordestina, Tamashiro propõe os pressupostos da etnomatemática como uma forma de encurtar caminhos para o aprendizado de matemática e torná-lo mais prazeroso tanto para os discentes quanto aos docentes.

Retomando ao campo da linguagem, concluímos este dossiê com o texto de Francisco Jeimes de Oliveira Paiva, docente da Secretaria da Educação do Estado do Ceará (SEDUC/CE) cujo título é Um estudo contrastivo de considerações finais de dissertações de mestrado escritas por pesquisadores da cultura (inter)disciplinar em História e Letras. Em seu texto, o professor Paiva objetiva analisar as práticas discursivas e os movimentos retóricos de seções de considerações finais de dissertações de mestrado dos cursos em pauta por meio da perspectiva da análise sociorretórica de John Malcolm Swales do Instituto de Linguagens da Universidade de Michigan.

A dispersão livre e aberta do conhecimento, ao mesmo tempo que potencializa reflexões sobre os seus modos de produção, exige que nos distanciemos de dogmas positivistas, porém sem perder o devido e equilibrado rigor científico a fim de estabelecer pontes dialógicas entre distintos campos de saber. Espero que os leitores deste primeiro número da Revista Interdisciplinar em Estudos de Linguagem sintam-se contemplados com a variedade de manuscritos que oferecemos.

Isso posto, que rufem os tambores e soem os clarins, pois a RIEL está no ar! 